\title{
The characterisation by luminescence spectroscopy of uranium(VI) incorporated into zeolites and aluminas
}

\author{
M.E.D.G. Azenha*, M. da Graça Miguel, S.J. Formosinho, H.D. Burrows \\ Departamento de Química, Universidade de Coimbra, 3049 Coimbra, Portugal
}

Received 31 August 2000; accepted 29 September 2000

\begin{abstract}
Luminescence spectroscopy of solids at $77 \mathrm{~K}$ has been used to characterise the uranium(VI) species incorporated into $\alpha$-alumina, $\gamma$-alumina and zeolites Y and ZSM-20 by adsorption from solution and into ZSM-5 by chemical synthesis. With uranyl adsorbed from nitrate solutions onto $\alpha$ - and $\gamma$-aluminas, the luminescence measurements show the dominant uranium species is schoepite, $\mathrm{UO}_{3} \cdot x \mathrm{H}_{2} \mathrm{O}$, in agreement with results from X-ray diffraction and Raman spectroscopy. With uranyl acetate, there are indications that a crystalline acetate species is also present. With zeolite-Y and ZSM-20, the main species is a dimer. In addition, some monomeric $\left[\mathrm{UO}_{2}\left(\mathrm{H}_{2} \mathrm{O}\right)_{5}\right]^{2+}$ is also present. With ZSM-5, although this is not observed in X-ray diffraction, the luminescence spectrum shows the presence of a species, similar to the schoepite seen with the aluminas. It is suggested that this may be due both to closely related polymeric species, and to uranyl anions, such as $\left[\mathrm{UO}_{2}(\mathrm{OH})_{4}\right]^{2-}$ and $\left[\mathrm{UO}_{2}(\mathrm{OH})_{3}\right]^{-}$. (C) 2001 Elsevier Science B.V. All rights reserved.
\end{abstract}

Keywords: Uranyl ion; Aluminas; Zeolites; Adsorption; Luminescence spectroscopy

\section{Introduction}

There is currently considerable interest in the incorporation of the uranyl ion into solid matrices. This stems from the needs of incorporating nuclear wastes in inert solids for long-term storage [1,2], the possibility of using excited uranyl ion as a photocatalyst [3-5] and the potential that uranium oxides have as efficient catalysts for the thermal degradation of pollutant molecules [6,7]. However, to understand these systems, it is important to obtain information on the way that uranium is incorporated.

The uranyl ion possesses a well-characterised lumi-

\footnotetext{
* Corresponding author. Tel.: +351-239-852080; fax: +351-239827703.

E-mail address: meazenha@ci.uc.pt (M.E.D.G. Azenha).
}

nescence [8], and it has been shown that this can be used for giving detailed structural information on a variety of systems [9]. In this paper we report the application of this to the determination of the uranium(VI) species incorporated into some aluminas and zeolites.

\section{Experimental}

All chemicals were of the purest grade available and were used without further treatment. With $\alpha$ and $\gamma$-alumina and zeolites Y and ZSM-20, uranyl was incorporated by stirring the solid in a solution of uranyl nitrate or acetate of appropriate $\mathrm{pH}$ for $24 \mathrm{~h}$ and then filtering and drying [10]. Uranyl ions are retained by the solid and do not leach out when treated with water. This is important for the 

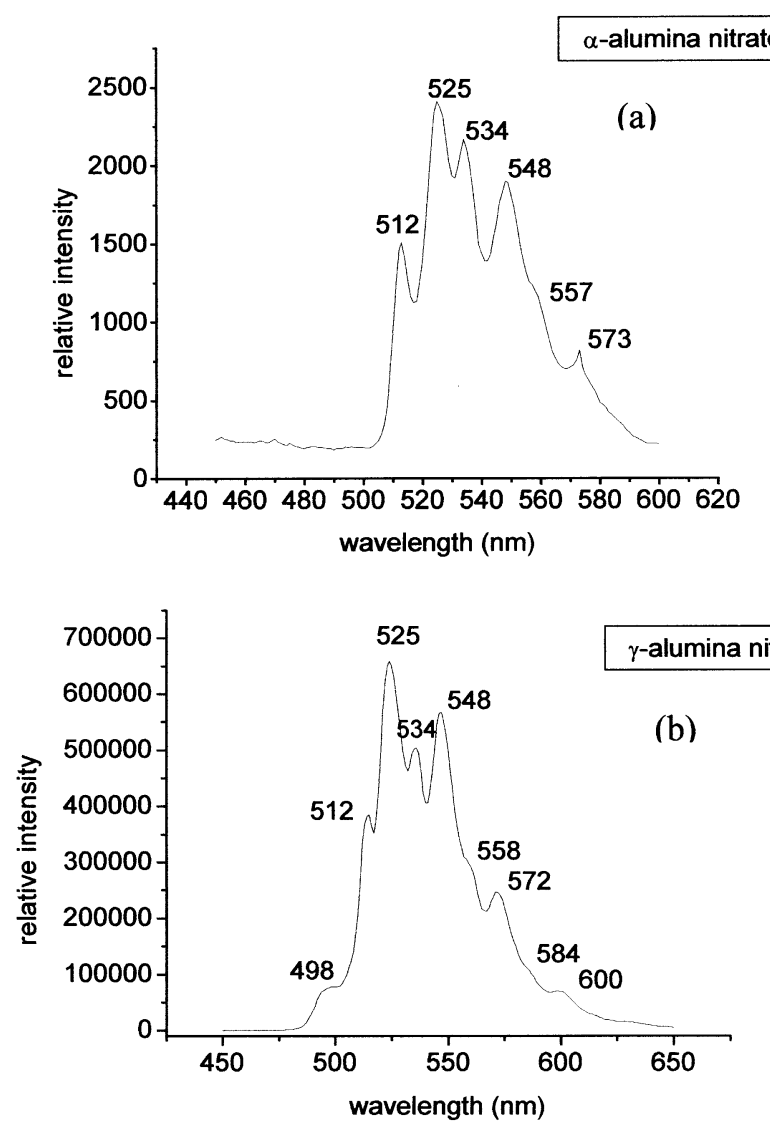

Fig. 1. Luminescence spectra at $77 \mathrm{~K}\left(\lambda_{\text {excit }} 337 \mathrm{~nm}\right)$ of uranyl incorporated from nitrate solutions in: (a) $\alpha$-alumina (pH 3.8); and (b) $\gamma$-alumina (pH 2.8).

potential applications of these systems for uranium immobilisation. All samples were characterised by $\mathrm{X}$-ray diffraction, scanning electron microscopy and vibrational spectroscopy [10]. It was not possible to incorporate uranyl ion into zeolite ZSM-5 in this way. Instead, this was chemically synthesised by a literature procedure [11]. This involved heating uranyl acetate, silica, alumina and base $(\mathrm{pH}$ $10.5-11)$ in an autoclave at $160^{\circ} \mathrm{C}$, using a U/Al ratio $\approx 0.75$. The product was filtered, washed with water and dried at $120^{\circ} \mathrm{C}$. Crystallinity of the uranium incorporated ZSM-5 sample was conformed by SEM-EDX and X-ray diffraction. Luminescence spectra were recorded at $77 \mathrm{~K}$ on a Spex Fluorolog 2 spectrofluorimeter.

\section{Results and discussion}

X-ray diffractograms of products of adsorption from uranyl nitrate solution onto $\alpha$ - and $\gamma$-alumina supports were practically identical, except for reflections assigned to the supports. The peaks due to the adsorbed uranium(VI) species correspond to those of schoepite $\mathrm{UO}_{3} \cdot x \mathrm{H}_{2} \mathrm{O}(1<x \leq 2)$. This is supported by Raman spectra, which are identical to literature data for schoepite [12]. Luminescence spectra were run at $77 \mathrm{~K}$ (Fig. 1). These are similar for the two aluminas, and show one well-defined progression at $512,534,558$ and $586 \mathrm{~nm}$, due to $\mathrm{UO}_{3} \cdot x \mathrm{H}_{2} \mathrm{O}$. This has a vibrational progression $805 \pm 2 \mathrm{~cm}^{-1}$ due to the $\mathrm{O}=\mathrm{U}=\mathrm{O}$ symmetric stretch. A second progression is 

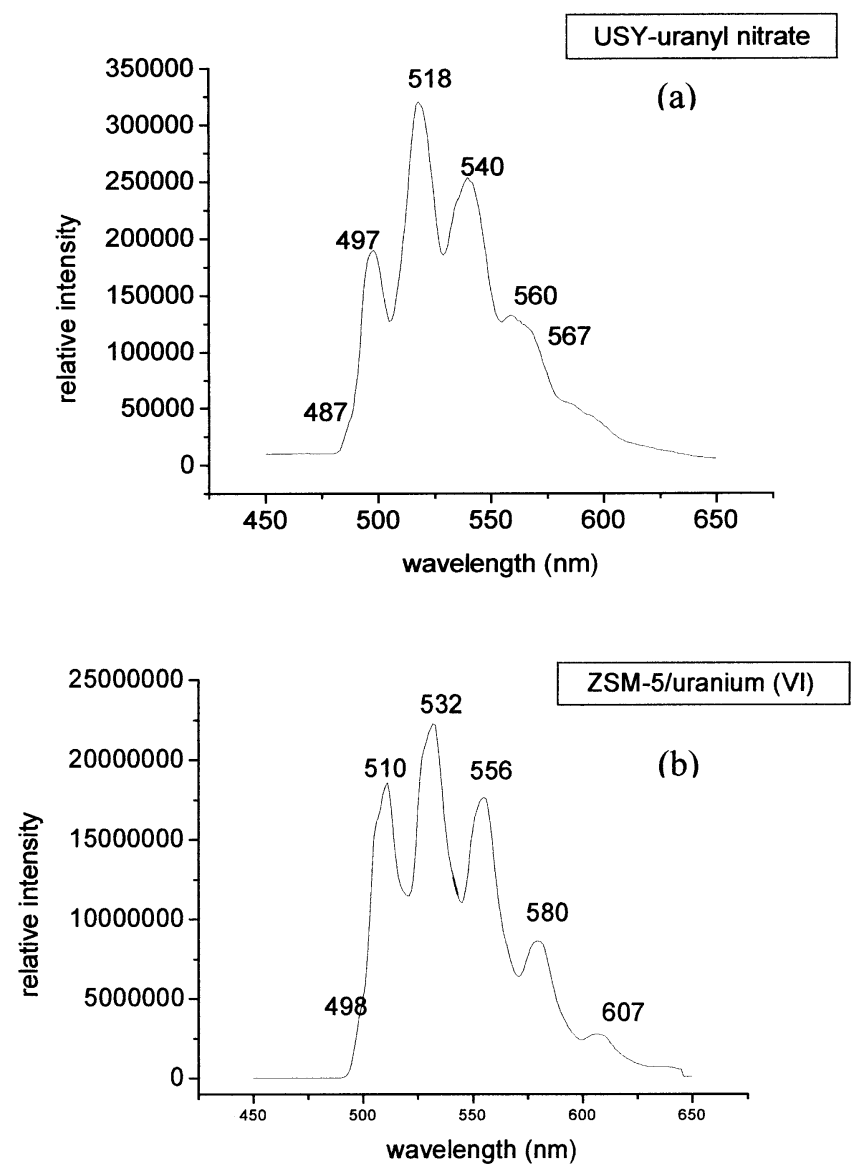

Fig. 2. Luminescence spectra at $77 \mathrm{~K}\left(\lambda_{\text {excit }} 337 \mathrm{~nm}\right)$ of uranyl ion incorporated into: (a) zeolite-Y (pH 2.1); and (b) ZSM-20.

observed in both cases at 525, 548 and $572 \mathrm{~nm}$, which is probably associated either with a different adsorption site or hydrolysed uranyl species. The zero phonon line, at $504 \mathrm{~nm}$, is seen in the excitation spectrum. In addition, a weak band at $495 \mathrm{~nm}$ is seen in the $\gamma$-alumina. On adsorption from uranyl acetate solutions, crystalline acetate species were present in addition to the hydrated uranium(VI) oxide. More details on these are obtained by luminescence spectra down to $4 \mathrm{~K}$, as discussed elsewhere [10].

The luminescence behaviour of uranyl incorporated into zeolite-Y and ZSM-20 are similar, as expected from the similarities in structure. The luminescence spectra, shown for zeolite-Y in Fig. 2(a), show two progressions. The first, weaker, feature starts at $487 \mathrm{~nm}$, and corresponds to the species
$\left[\mathrm{UO}_{2}\left(\mathrm{H}_{2} \mathrm{O}\right)_{5}\right]^{2+}$. This is supported by the excitation spectra $\left(\lambda_{\mathrm{em}} 487 \mathrm{~nm}\right)$ [10], which is identical, with the same vibronic progression $\left(\nu_{1}=705 \mathrm{~cm}^{-1}\right)$, to that observed for this species in uranyl nitrate glasses in glycerol-water at low temperature [13]. The dominant feature in the uranyl/zeolite-Y luminescence (Fig. 2(a)) starts at $493 \mathrm{~nm}$, and shows a vibrational progression $824 \pm 2 \mathrm{~cm}^{-1}$, suggesting a strong equatorial coordination of the uranyl ion. This is attributed to the dimeric species, $\left(\mathrm{UO}_{2}\right)_{2}(\mathrm{OH})_{2}$, present in the zeolite cavities.

For the synthesised ZSM-5, the luminescence spectrum at $77 \mathrm{~K}$ (Fig. 2(b)) shows some similarities to those observed with uranyl in the aluminas, where the dominant species is schoepite, $\mathrm{UO}_{3} \cdot x \mathrm{H}_{2} \mathrm{O}$. Although in X-ray diffraction only a single phase 
was observed, and this species was not detected, from the emission spectrum, it is likely that in ZSM-5 there are species with a very similar structure. These are probably polymeric species, together with some mononuclear ions such as $\left[\mathrm{UO}_{2}(\mathrm{OH})_{4}\right]^{2-}$ and $\left[\mathrm{UO}_{2}(\mathrm{OH})_{3}\right]^{-}$, as anticipated from the high $\mathrm{pH}$ at which the zeolite was synthesised.

In conclusion, uranyl luminescence provides an excellent method for studying the nature of the uranium(VI) present in zeolites and aluminas, and confirms the presence of various monomeric and polymeric species.

\section{Acknowledgements}

We are indebted to Professor E. Derouane and Dr Z. Gabelica for the facilities and expertise provided for zeolite synthesis. Financial assistance from the Fundação Calouste Gulbenkian and PRAXIS XXI is gratefully acknowledged.

\section{References}

[1] D.E. Morris, P.G. Allen, J.M. Berg, C.J. Chisholm-Brause, S.D. Conradson, R.J. Donohue, N.J. Hess, J.A. Musgrave, C.D. Tait, Environ. Sci. Technol. 30 (1996) 2322.

[2] M.T. Olguín, M. Solache-Ríos, D. Acosta, P. Bosch, S. Bulbulian, Microporous Mesoporous Mater. 28 (1999) 377.

[3] S.L. Suib, K.A. Carrado, Inorg. Chem. 24 (1985) 863.

[4] Y. Mao, A. Bakac, Inorg. Chem. 35 (1996) 3925.

[5] S. Dai, D.H. Metcalf, G.D. Del Curl, L.M. Toth, Inorg. Chem. 35 (1996) 7786

[6] G.J. Hutchins, C.S. Heneghan, I.D. Hudson, S.H. Taylor, Nature 384 (1996) 341.

[7] S.D. Pollington, A.F. Lee, T.L. Overton, P.J. Sears, P.B. Wells, S.E. Hawley, I.D. Hudson, D.F. Lee, V. Ruddock, Chem. Commun. (1999) 725.

[8] C.K. Jorgensen, R. Reisfeld, Struct. Bonding 50 (1982) 119.

[9] H.D. Burrows, M. da G. Miguel, Adv. Colloid Interface Sci. (2000) (in press).

[10] M.E.D.G. Azenha, PhD thesis, University of Coimbra, 1998.

[11] R.J. Argauer, G.R. Landolt, US Patent 3702 886, 1972.

[12] L. Maya, G.M. Begun, J. Inorg. Nucl. Chem. 43 (1981) 2827.

[13] H.D. Burrows, S.J. Formosinho, F. Pinto Coelho, M. da G. Miguel, M.E.D.G. Azenha, Mem. Acad. Ciências Lisboa 30 (1989) 33. 